\title{
Persuasive Mobile Device Sound Sensing in a Classroom Setting
}

\author{
http://dx.doi.org/10.3991/ijim.v7i1.2262 \\ Arttu Perttula ${ }^{1}$, Jari Multisilta ${ }^{2}$ and Pauliina Tuomi ${ }^{1}$ \\ 1 Tampere University of Technology, Pori, Finland \\ 2 University of Helsinki, Helsinki, Finland
}

\begin{abstract}
This paper presents an idea on how to utilize mobile phones to support learning in the classroom. The paper also tries to initiate discussion on whether we can create new kinds of learning applications using mobile devices and whether this could be the way we should proceed in developing 21st century learning applications. In this study, a mobile phone is programmed to function as a collective sound sensor. To achieve an appropriate learning atmosphere, the designed system attempts to maintain the noise level at a comfortable tolerance level in the classroom. The main aim of the mobile application is to change student behaviour through persuasive visualizations. The prototype application was piloted during spring 2012 with a total of 72 students and two teachers. The results, based on observations and interviews, are promising and several subjects for future work arose during the pilot study.
\end{abstract}

Index Terms —classroom, mobile, learning, persuasion

\section{INTRODUCTION}

There has been a lot of discussion and research on mobile learning or m-learning, and learning theories for eLearning, web-based learning, and mobile learning [1, 2, $3,4,5,6,7]$. The first research pilots on mobile learning were based on transferring electronic content to mobile phones. Soon, it was realized that mobile learning should not just copy the "old" practices of eLearning but the strengths of the mobile device should be harnessed in some other way for learning purposes. With the technology developing at a rapid pace, we soon had mobile phones with digital cameras. The mobile phone appeared as a tool for creating digital recordings of learning activities, for example on field trips [8].

The next innovations in mobile devices are sensors [9]. In general, a sensor is a small device that observes its environment and reports back to a remote base station [10]. Many mobile phones already have a GPS $^{1}$ feature that can be used to add location information for mobile applications. Some devices have motion sensors that monitor the acceleration and movements of the device in three dimensional space. It is also possible to use a heart rate monitor with a mobile phone for monitoring physical exercise. In addition, mobile phones can observe the ambient light or sound level from the surroundings of the device.

The data collected from the surroundings of the device can be used to determine something about the context where the device and the user are. The context can then be

${ }^{1}$ The Global Positioning System provides location information based on satellites. used in personalizing the mobile services we use with our mobile devices. There are already applications that can suggest a good restaurant or store nearby, based on our location. Could context and sensor data be used in creating new kinds of mobile learning applications? Sharples [11] argues that "the main barriers to developing these new modes of mobile learning are not technical but social”. According to Sharples [11], we need more understanding of context and the role of new mobile technologies in the learning process.

This paper presents a novel idea of how to utilize mobile phones to support learning in the classroom. The paper also tries to initiate discussion on whether we can create new kinds of learning applications using mobile devices and whether this could be the way we should proceed in developing 21st century learning applications. The 21st century skills and learning applications can be defined in terms of knowledge, skills, attitudes, values and ethics, and they describe the skills that are needed in understanding information in the information society [12]. In this study, a mobile phone is programmed to function as a collective sound sensor. To achieve an appropriate learning atmosphere, the system presents persuasive visualizations to a target group of students. Thus it attempts to maintain noise levels at pleasurable tolerance level in the classroom.

According to Bistrup et al. [13], harmful effects of noise on children consist of both auditory and nonauditory effects. Auditory effects are reduced or impaired hearing or temporary threshold shifts or tinnitus. This is probably not a relevant problem in classroom settings but when it comes to the non-auditory effects of noise, which are mainly cognitive effects, there is something to improve. Noise can negatively affect children's learning and language development, can disturb children's motivation and concentration and can result in reduced memory and reduced ability to carry out more or less complex tasks. Noise may provoke a stress response in children that includes increased heart rate and increased hormone response, and noise may disrupt sleep and hinder the necessary recovery of the body and brain. As an indirect effect of noise, a raised voice may lead to hoarseness and vocal nodules [13]. In other words, noise in classrooms is a problem and furthermore a challenging research problem.

Bistrup et al. [13] have provided guidelines for achieving good classroom acoustics. In addition to these instructions, mobile technology could be used to prevent the noise problem. Instead of traditional mobile learning applications that are learning tools or information providers, this novel solution has a different approach to support 
and enhance learning. The main aim of the collective sound sensing mobile application is to change student behaviour through persuasion. More detailed purposes of the application are: 1) to keep the soundscape in the classroom appropriate for learning, 2) teach students to work as a team, 3 ) teach them to take others into consideration, 4) teach proper behaviour and 5) provide something fun to create and enrich a positive learning experience. Furthermore, it can be used to teach sound pressure levels. The prototype application was piloted during the spring of 2012 with a total of 72 students and two teachers. The results based on observations and interviews are promising and several topics for future work arose during the pilot study.

\section{CONTEXT}

This study tries to answer the following research question: how can we reduce noise in the classroom and thus support learning? To attain an appropriate learning atmosphere, the designed system attempts to keep the noise level at pleasurable tolerance level in the classroom. The hypothesis is that through mobile persuasion, learning results will improve. To understand the context of the study better, mobile learning and persuasion are described in more detail below.

\section{A. Mobile Learning}

Lonsdale et al. [14] suggested that contextual information should be used in mobile learning to deliver the right content and services to the user. This could help to overcome the limitations of mobile devices related to user interface and bandwidth. A context, according to Lonsdale et al. [14], is understood as a combination of an awareness of current technical capabilities and limitations and the needs of learners in the learning situation.

The concept of context is also related to the concepts of adaptive, pervasive and ubiquitous learning. For example, Syvänen et al. [15] presented experiences of developing an adaptive and context-aware mobile learning system that they also describe as a pervasive learning environment. They define the pervasive learning environment as a single entity formed by the overlapping of "mental (e.g. needs, preferences, prior knowledge), physical (e.g. objects, other learners close by) and virtual (e.g. content accessible with mobile devices, artefacts) contexts."

Sharples et al. [6] explains that computer technology and learning are both ubiquitous. The concept of mobile learning is closely related to ubiquitous learning and context-aware ubiquitous learning. A context-aware ubiquitous learning system integrates authentic learning environments and digital (virtual) learning environments, which in turn will enable the learning system to interact more actively with the learners. This is possible because of current mobile devices and sensors, such as RFID ${ }^{2}$. [16] It can be said that learning in a classroom can be ubiquitous.

Yau and Joy [17] presented three different types of context-aware mobile learning applications: locationdependent, location-independent and situated learning. They also present a theoretical framework for mobile and context-aware adaptive learning. In their framework, they use contexts such as the learner's schedule, learning

\footnotetext{
${ }^{2}$ Radio-frequency identification is a wireless short distance system that
} uses electromagnetic fields to transfer data. styles, knowledge level, concentration level and frequency of interruption.

\section{B. Mobile Persuasion}

Many people do not need external pressure or rewards to do things like reading books; the rewards are built-in, or intrinsic [18]. Malone and Lepper [19] have outlined different types of intrinsic motivators. Three of these motivators are group-level intrinsic motivators: competition, cooperation, and recognition. They involve interaction among people. According to Fogg [18], competition is perhaps the most powerful group-level intrinsic motivator. However, not everyone is competitive by nature, but in most situations and for most people, competition is energizing and motivating. Cooperation is another motivator, one that seems to be built into human nature. When people belong to a work group, most of them cooperate. Finally, people are intrinsically motivated by recognition. [18]

The system presented in this study utilizes these three motivators in particular. Classrooms can compete against each other to find out the best learning atmosphere. Also, students can challenge each other to obtain positive collective results. To maintain a suitable noise level, cooperation is essential. Students and teachers can discuss the study results together. Thus, by offering public recognition, the system can increase the likelihood that the group of students will adopt the target behaviour.

In addition to group-level intrinsic motivators, the system involves four other mobile persuasion principles: kairos, information quality, social facilitation and social comparison. Mobile devices are ideally suited to leverage the principle of kairos; offering suggestions at opportune moments to increase the potential to persuade [18]. The designed system in this study visualizes the current noise level in real-time with suggestive images. Visualizations also take information quality into consideration; computing technology that delivers current and relevant information has greater potential to create behaviour change. Furthermore, when it comes to social facilitation, people are more likely to display the target behaviour if they know they are being observed via computing technology or if they can discern via technology that others are displaying the behaviour along with them. According to the social comparison principle, people will have greater motivation to display the target behaviour if they are given information, via computing technology, about how their performance compares with the performance of others, especially others who are similar to them. With their ubiquity, mobile phones have already demonstrated their value as a persuasion tool in several cases, for example education and health. [18]

\section{RELATED WORK}

Several studies have been made about mobile learning $[1,2,3,4,5,6,7]$ and persuasion [18]. The intention of this study is to change student behaviour through persuasion based on the collective mobile sound sensor. Thus it is more relevant to present some related research concerning mobile sound sensing and noise for background information. There are also noise prevention studies, which utilize external sound sensors instead of mobile phones (e.g. [20]). Commonly, noise measurement or prevention studies are conducted in urban environments and are outside the learning context. 
Maisonneuve et al. [21] presented an approach called NoiseTube for the assessment of noise pollution involving the general public. The goal of this project was to turn GPS-equipped mobile phones into noise sensors that enable citizens to measure their personal exposure to noise in their everyday environment. Thus, each user can contribute by sharing their geo-localised measurements and further personal annotation to produce a collective noise map.

The MobGeoSens system [22] utilizes built-in microphones and other sensors attached to mobile phones to collect different kinds of pollutant levels in an urban environment. It also adds the dimension of spatial localization to the data collection process and provides the user with both textual and spatial cartographic displays. While collecting the data, individuals can interactively add annotations and photos which are automatically added and integrated in the visualization log.

Within the Nericell project [23], audio recordings from the built-in microphone of a smartphone constitute the input of a honk-detection algorithm, which in turn feeds an estimator of current traffic conditions. Sensors and radios are used to detect bumps and potholes, braking and honking, and to localize the phone in an energy-efficient manner. The authors investigated the influence of background noise and the sensitivity of the microphones on the performance of the honk-detector.

CenceMe [24] combines the inference of the presence of individuals using sensor-enabled mobile phones with the sharing of this information through social networking applications like Facebook and Twitter. The system also captures audio signals. The data is processed on the mobile phone to determine whether it contains voices or just background noise.

Misra et al. [25] present several examples of how mobile phone microphones can be used for music applications. Using simple feature extraction methods, parameters can be found that sensibly map to synthesis algorithms to allow expressive and interactive performance. For example, a blowing noise can be used as a wind instrument excitation source. Also, other types of interactions can be detected via microphones, such as striking.

The BikeNet project [26] presented how average noise levels can be used to influence daily decisions like the choice of cycling route. The prototype derives estimations of the actual noise levels in the immediate vicinity of the cyclist. The system provides quantitative guidance to cyclists about the healthiness of a given route in terms of pollution levels, allergen levels, noise levels, and roughness of the terrain. These measurements, together with data from cyclist performance measurements, are correlated to create a holistic picture of the cycling experience.

Furthermore, in addition to mobile phone sound sensing, for example Bistrup et al. [13] and Klatte et al. [27] have studied the effects of classroom acoustics on performance and well being in elementary school children. According to the authors, the acoustical conditions in classrooms often do not suit the specific needs of young listeners. They found that reverberation had a significant effect on speech perception and short-term memory of spoken items. The results highlight the importance of good acoustical conditions in classrooms.

Based on the background research, this paper presents a novel approach. Different solutions can be compared but currently there are no applications with this kind of implementation and purpose. The following chapter describes the prototype in detail.

\section{PRototype Implementation AND DESIGN}

An initial approach (Figure 1.) was present decibel ${ }^{3}$ readings on a television screen (Figure 2.). Basically, it presents the suitability of the current soundscape in a classroom. The solution utilizes one mobile phone for sound monitoring and one external display for visualization (Figure 2.). In this version, decibels were divided into three categories: quiet, tolerable and noisy. Numbers were colored green, yellow or red based on those categories. Threshold limits were adjustable. There were some difficulties with this approach: numbers were delayed couple of seconds, it might take too much attention, there are already commercial solutions like this and probably it is not persuasive enough.

The second version was designed to solve those grievances. Basically, only visualizations (Figure 3.) are different and there is a gamification ${ }^{4}$ element; too noisy environment causes "a game over" visualization and sound level measuring ends up. Thus, this custom-made application can be considered also as a persuasive game, data visualization or interactive teaching material. Graphics (Figure 3.) were created to be suitable and entertaining for different age groups from 6 to 18 years. It was also topical with the seasonal Easter time decorations when the pilot study was carried out. Furthermore, any child or young person could draw it. Hence, it was easy to identify with and the design was attractive to the target group.

The Python for $560^{5}$ application processes two sound files simultaneously: it records two seconds of the present soundscape to one WAV-format file (Figure 6.) and meanwhile it calculates decibel readings (Equation 1.) from another file recorded previously. Every two seconds it swaps these files. Thus, there is a two-second delay between the captured sounds and the visualized image (Figure 3.), which is still eligible for this purpose. The view of the mobile phone is transferred in real time from
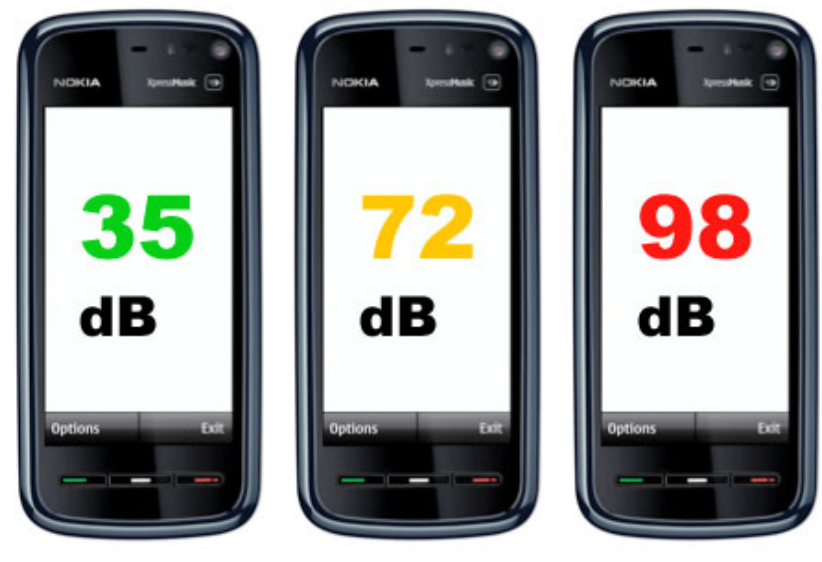

Figure 1. An initial approach with colored decibel readings based on three categories: quiet, tolerable and noisy

${ }^{3}$ The decibel $(\mathrm{dB})$ is a logarithmic unit that indicates the ratio of a physical quantity relative to a specified or implied reference level. [28] ${ }^{4}$ Gamification enhances non-game contexts by game design elements, thinking and mechanics. [29]

${ }^{5}$ The Python for S60 (PyS60) is Nokia's version of the Python programming language to its Symbian S60 software platform. [30] 
the phone's s-video output to a data projector or a large television screen. Thus, everyone in the classroom is able to monitor it.

Without proper calibration, sensor devices produce data that may not be representative or can even be misleading [21]. In this case, for example the length of the s-video cable determines the place of the phone (Figure 4.). The best location would be probably in the middle of the classroom. The application is not able to be aware of the distance of the sound source. Thus it is also more proper to calculate estimate sound pressure values and visualize it in pictures than in concrete numbers. In addition, to ensure decent functioning while a lesson a charger cable should be connected to the phone also.

The prototype version is manually adjustable. Firstly, the main user, in this case a teacher, is able to adjust two suitable decibel-reading limits (Figure 5.) from the options menu. This may vary depending on the mobile phone utilized and the location of the phone in the classroom. If the sound pressure level exceeds the first limit, the second view is visualized (Figure 3.). If the sound pressure level also exceeds the second limit, the visualization ends up in the final phase (Figure 3.) and this is visualized until the sound monitoring is restarted. The initial prototype had only these two decibel reading limits (Figure 6.).

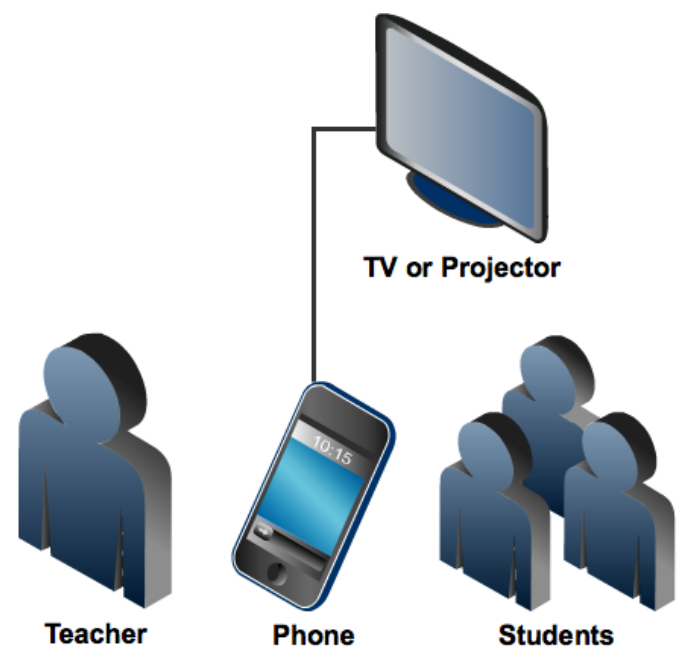

Figure 2. The system architecture of the collective sound sensor
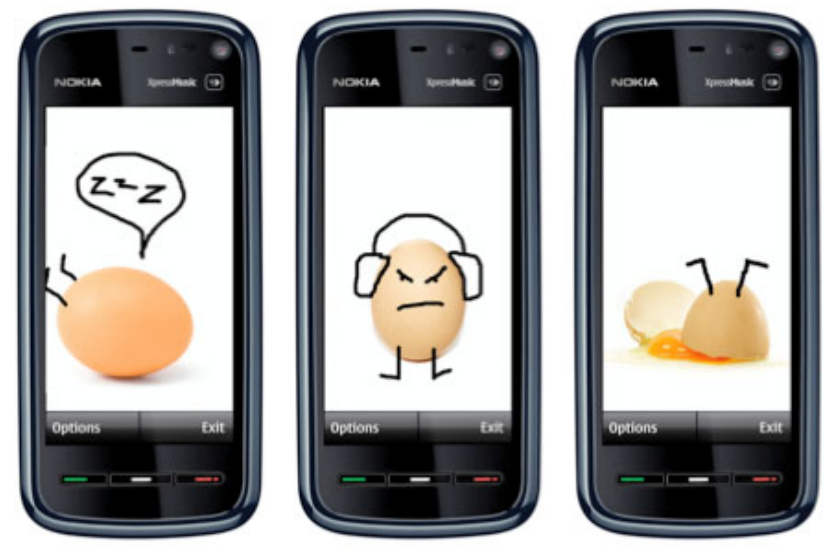

Figure 3. Three views of the prototype mobile application (from left to right): 1) measured sound pressure level is tolerable, 2) the sound pressure level is not appropriate and 3) the sound pressure level has exceeded the tolerable zone
Because one unintentional loud sound could trigger "the game over" event in this case, a manually adjustable limit exceeding option was added. For example, if the second sound pressure level is ten times above the selected limit, only after that will the visualization show the final phase. Once manual calibration is done, a teacher only has to start recording before a lesson by selecting start from the options menu.

Noise level or loudness (Figures 6. and Equation 1.) is generally measured as the equivalent continuous sound level (Leq). Measured in decibels, Leq captures the sound pressure level of a constant noise source over the time interval $\mathrm{T}$ that has the same acoustic energy as the actual varying sound level pressure over the same interval. A human ear perceives the loudness differently depending on the frequency of the sound. Standard weighted scale frequency functions have been developed to reflect human perception. [21] The mobile application contains a signal processing algorithm which measures the loudness level of the microphone recording the environmental sound over two seconds at a chosen interval. A commonly used [21] A-weighting filter is applied to the recorded sound and the equivalent sound level Leq, measured in $\mathrm{dB}(\mathrm{A})$, is then computed (Equation 1.).

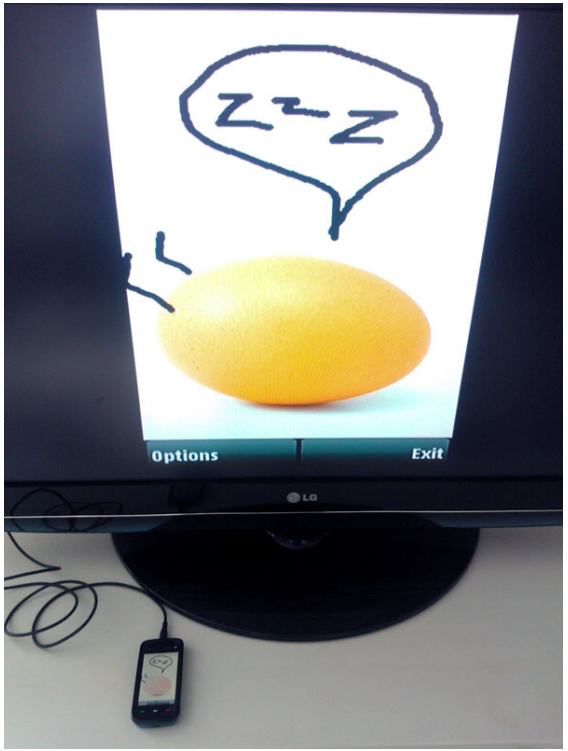

Figure 4. A demonstration setup with a phone and a television
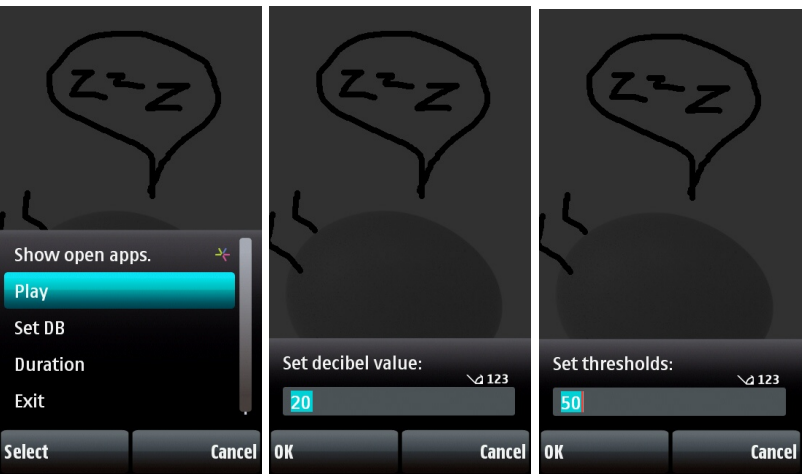

Figure 5. Menu as seen on the screen 
PAPER

Persuasive Mobile Device Sound Sensing in a ClassRoom Setting

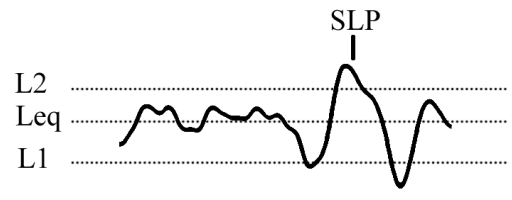

Figure 6. Recorded sound level pressure (SLP) and threshold limits L1 and L2. Presented wave and levels are examples

$$
L_{e q}=10 \log \frac{1}{T} \int_{0}^{T} \frac{p^{2}}{p_{0}^{2}} d t
$$

The idea is related to the concept of opportunistic sensing, where the data collection stage is fully automated with no user involvement. The benefit of opportunistic sensing is that it lowers the burden placed on the user, allowing overall participation by a population of users to remain high even if the application is not that personally appealing. This is particularly useful for community sensing, where per user benefit may be hard to quantify and only accrue over a long time. [31]

\section{PILOT STUdy}

A five-day pilot test was conducted in the spring of 2012 (March 26-30) with the cooperation of Meri-Pori (Pori, Finland) upper level school and upper secondary school. Two teachers (mother tongue and physics) and four classes (two secondary schools and two high schools) of students (altogether $n=72$, girls and boys, age 13-18) participated in the pilot. The system was installed in the classroom beforehand and the teachers were told to conduct as ordinary a lesson as possible. The teachers did not tell the students what was going on. A mobile phone was connected to a television or a video projector depending on the classroom equipment and the entire system was visible to the students.

\section{A. Research Methods}

In this case, the interest lies in the experience. In other words, how the teachers and students experienced the pilot situation. Does the system affect the behaviour of the students and hence the atmosphere of the class? This can be seen as a user experience study. Currently, the most common methods of assessing user experience are through subjective self- reporting and through objective reports [32].

In this study, objective reports were based on observations performed by teachers. This method was selected because it enabled the observation of participants during ordinary lessons. The teachers were interviewed after each lesson. In particular, the teachers tried to observe behaviour and social interaction. Self-reporting included informal conversations with teachers, although the teachers talked to the students and reported back on the students' thoughts. It is difficult to measure the effects on the learning process; hence only teachers provided study feedback.

\section{B. Results and Findings}

Based on the observations, high school students (age 16-18) were not excited about the application. All in all, it did not have an effect on them at all. They wondered about the system for a while but then no longer paid any attention to it. According to the teachers, noise is not a relevant problem among this age group hence the application was not meaningful. Also, visualization might be more appealing to younger students. Secondary school students were eager to know about the system. Although there was no animation and the graphics were simple, secondary school students (age 13-15) reported that the visualization was fun and entertaining. However, one teacher indicated that the application did not disrupt the students' learning process because of it did not require a lot of attention. Secondary school students quickly learned the meaning and function of the application.

Students tried to maintain an appropriate sound level in the classroom because they did not want to break the visualized egg. The application clearly had a persuasive effect on the students. They learned the differences between proper and inappropriate sound levels. In fact, they perceived the experiment as a game. If someone was too noisy the others instructed the disruptive student to be quieter. Team spirit improved significantly during the pilot study. They perceived the application as such a challenge that they discussed among themselves during breaks how they could keep the egg unbroken for as long as possible. During the pilot week, the students asked the teacher if they would have the experiment during the next lesson. And if the answer was no, they were disappointed. Other classes would have liked to try the system, too.

The teachers reported that it would be useful and interesting if it were possible to locate the noise more specifically in the classroom because it is not always obvious who the troublemaker is. Using three or more mobile phones to detect noise could fulfill this task, making it possible to locate the sound source approximately; similarly to the way an indoor positioning system utilizes three or more Wi-Fi hotspots. The teachers also had another kind of concern. They became anxious about whether their teaching performance could be recorded and monitored via this system. A class with the most suitable sound levels during lessons possibly indicates a skillful teacher.

Regarding the technology, the study revealed that the phone's (Nokia XpressMusic 5800) microphone or software is probably optimized for speech. For example, sounds from whistling and hand clapping had a random effect on decibel readings, whereas speech and shouting worked more precisely. In other words, the mobile phone utilized and the quality of its microphone might have an effect on the final experience. In any case, in this pilot study case it did not have significant impact on the results.

\section{DISCUSSION AND IDEAS}

Based on the study results, it is obvious that the target group should be determined more precisely. In its current state, the application could also be useful among kindergarten (age 2-5) and primary school (age 6-12) students. Students could draw and upload their own character images or animations to the application. In this way, the application could have an even greater impact on the target group.

Actually, various studies have shown that noise levels in day-care rooms and play areas can be considerable and that these may have negative effects $[33,34,35,36,37$, 38] In addition to kids, these effects concern teachers as well. Noise levels in day-care centres are occasionally high, possibly resulting in health repercussions: auditory fatigue and stress being the two main negative effects. [33, 
34, 38] The stress of the day-care centre employees (in this case caused by the noise) can eventually lead to burnout and work fatigue. Work fatigue can be described as being a serious stress symptom disorder that appears trough physical and mental fatigue, lack of professional confidence and cynical attitude towards work [39, 40]. Overall, stress can be seen as one of the most significant factors behind work fatigue. [41, 42, 43]

Furthermore, high noise levels may lead to irritability, difficulty communicating, reduced intelligibility and even to a reduction in verbal acquisition amongst children [33]. Several solutions have already been identified and implemented in order to reduce noise levels at day-care centres: cutting down on the number of children at each location, placing tennis balls under chair legs and modifying the choice of activities and toys. [33, 36] Another way of reducing noise in day-care centres is by adding absorbent acoustic materials. Presented persuasive mobile device sound sensing system could be utilized as a functional solution to reduce the noise in day-care centres by utilizing children's own motivation to keep quiet. The motivation is triggered by the system and its well-being.

To be even more persuasive, a class of students could receive stamps or awards if they succeed in noise prevention. Another option would be for classes to compete against each other. If students behave properly the application could offer tips and facts for learning besides the sound monitoring. The character could also encourage the students.

Another point of view is that there could be this kind of mascot or game in a classroom that could be taught by the students. The mascot could learn and acquire wisdom based on the classroom noise prevention results. Similarly, Ketamo and Suominen [44] have presented teachable octopuses based on geometry tasks. Basically, students would learn by teaching. Classrooms could compare and compete on their sound environments against other schools, even schools in other countries.

A more advanced version of the application could include a feature of the automatic recognition of different sounds. Selin et al. [45] have studied how harmonic and transient bird sounds can be recognized efficiently. The results indicate that it is possible to recognize bird sounds of the test species using neural networks with only four features calculated from the wavelet packet decomposition coefficients. A modified version of this kind of automatic sound recognition system could also be used in learning environments. It is likely that student voices could be recognized in a similar way to birds.

It should be taken into account that it was not studied during this pilot how noise affects to learning. There were no comparisons between silent and noisy classes or with and without the application. In this case, supposition that disturbing background noise has negative effect to learning is based on actualized references. Studies indicate that learning and teaching in classrooms is often impeded by noise and reverberation. Noise exposure in schools is often above reasonable limits for children. Learning in loud classrooms is especially impeded by poor speech intelligibility and decreased performance of learning. [46, 47, 48, 49] Furthermore, noise especially effects on cognitive performance, motivation and annoyance [50].

Even though there is evidence that noise of classroom decrease performance of learning, Lawrence [51] reported that certain kind of background music (for example classical) in a classroom could allow students perform manual tasks effectively and efficiently. The application presented could be enhanced with three types of background music based on three noise categories; classical music, pop music and hard rock. This might have an affect to the persuasiveness of the application.

As mentioned earlier, during this study, teachers were told to conduct as ordinary a lesson as possible and they did not tell the students what was going on. However the application could be utilized more pedagogically. A teacher could point out events of the application and highlight the persuasive meaning. The teacher and students could discuss together about noise; sources of noise, why there is noise and its affects to learning. In addition, the application could be utilized as a problem-solving task for students. They should understand how to succeed in this persuasive game and furthermore they should realize why it is important for them.

\section{FUTURE WORK}

In addition to further research, the next version of the presented system will work wirelessly using socket ${ }^{6}$ server solution (Figure 7.). It would be similar to that presented by Perttula et al. [52], but instead of $\mathrm{WLAN}^{7}$, networking will be conducted via the Internet. The installation and configuration will be more straightforward without a local network. In this second version, it would be possible to place the mobile phone wherever it is the most suitable. This solution also enables multiple phones to perform as a collective sound sensor. A computer or a device with Internet connection is needed to view the visualizations presented on a web page.

The advanced version will also include an automatic sound pressure level limit measurement option by recording average levels for a given period. In practice, a user does not manually set noise limits as presented in Figure 5. Determining the proper settings was timeconsuming during the pilot study because the selected readings were not comparable with decibels as mentioned earlier.

The next study will be conducted in day-care centres. They will probably benefit from it as discussed in previous chapter. According to Kyriacou [43] coping strategies

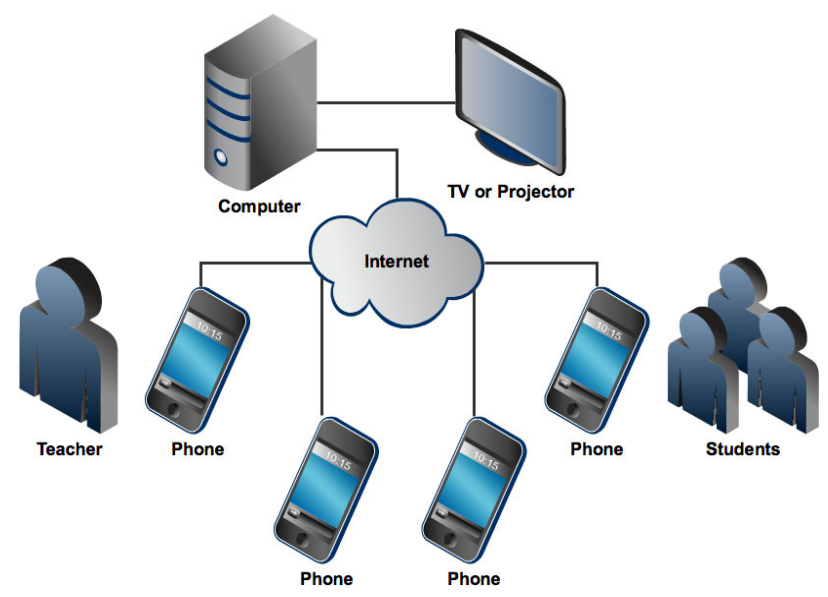

Figure 7. The system architecture of the planned second version

${ }^{6}$ A socket is an endpoint of an inter-process communication flow across a computer network.

${ }^{7}$ WLAN stands for a wireless local area network. 
can be divided into direct action and palliative techniques. Direct action refers to strategies teachers can do to eliminate sources of stress. For instance, if time pressures and deadlines are creating stress, a direct action to reduce the problem would be to seek a time extension, or to seek a change in deadline. Palliative techniques do not deal with the source of stress itself, but focus on reducing the feelings of stress from those sources. The presented system basically offers both of the coping methods since it can be used just to reduce the current noise in the room time to time/when needed or it can be used with the perspective that it eventually will drop the noise levels permanently when used regularly in daily basis.

The next study will also pay attention to pedagogically approach described in previous section. Teachers' role will be more active and thus benefits or disadvantages of the application will be studied more comprehensively. Also noise affects to learning will be studied and analyzed. Comparisons to previous studies' results of noise and learning will be conducted.

\section{CONCLUSIONS}

Noise can negatively affect children's learning and language development, can disturb children's motivation and concentration and can result in reduced memory and reduced ability to carry out more or less complex tasks [13]. To reduce noise in a classroom, this article presented a collective sound sensing system in the emerging fields of mobile learning, mobile persuasion and mobile phone sensing. The solution utilizes one mobile phone for sound monitoring and one external display for visualization of the suitability of the current soundscape in a classroom. The custom-made application with entertaining graphics can be considered as a persuasive game, data visualization or interactive teaching material.

Based on the results, the application managed to persuade students to behave more appropriately to create a suitable learning atmosphere in the classroom by reducing noise. As Lane et al. [31] have stated, understanding which types of metaphors and feedback are most effective for persuasion goals is still an open research problem. Building mobile phone sensing systems that integrate persuasion requires interdisciplinary research, combining behavioural and social psychology theories with computer science [31]. The use of large volumes of sensor data provided by mobile phones presents an exciting opportunity and is likely to enable new applications that have promise in enacting positive social changes in mobile learning over the next few years.

The combination of large-scale sensor data together with accurate models of persuasion could revolutionize how we deal with other learning issues in addition to noise in the classroom. Can we create new kinds of learning applications using mobile sensor networks and could this be the way we should proceed in developing learning applications for the 21st century? According to the present study, sensors provide new possibilities for learning applications. In addition, the understanding of sensorbased contextual data and the ability to apply this data to learning could also be considered a new kind of 21st century skill.

\section{ACKNOWLEDGMENT}

The authors would like to thank all the students who participated in the study. We also gratefully acknowledge teachers from Meri-Pori Upper Level and Meri-Pori Upper Secondary schools for providing expertise feedback.

\section{REFERENCES}

[1] D., Mwanza-Simwami, "Concepts and methods for investigating learner activities with mobile devices: an activity theory perspective,” in I. Arnedillo-Sánchez, M. Sharples, G. Vavoula (Eds.), Beyond Mobile Learning Workshop, Trinity College Dublin Press, 2007, pp. 24-25.

[2] L., Naismith, P., Lonsdale, G., Vavoula and M., Sharples, "Literature review in mobile technologies and learning," NESTA Futurelab Series, Report 11, Bristol, UK: NESTA Futurelab, 2004.

[3] M., Nichols, “A theory for eLearning,” Educational Technology \& Society, 6(2), 1-10, 2003.

[4] K., O’Brien, “New questions over Google's Street View in Germany," The New York Times, April 29, 2010, Available at http://www.nytimes.com/2010/04/30/technology/ 30google.html

[5] M., Oliver and C., Pelletier, “Activity theory and learning from digital games: developing an analytical methodology,” in D. Buckingham and R. Willett (Eds.), Digital Generations, Children, Young People, and New Media. Mahwah, New, Jersey, London: Lawrence Erlbaum Associates, Publishers, 2006.

[6] M., Sharples, J., Taylor and G., Vavoula, "Towards a theory of mobile learning," in proceedings of mLearn 2005 Conference, Cape Town, South Africa, 2005.

[7] A., Trifonova and M., Ronchetti, "Where is mobile learning going?,” in A. Rossett (Ed.), proceedings of World Conference on E-learning in Corporate, Government, Healthcare, \& Higher Education, Chesapeake, VA: AACE, 2003, pp. 1794-1801.

[8] R., Yeh et al., "ButterflyNet: a mobile capture and access system for field biology research,” in R. Grinter, T. Rodden, P. Aoki, E. Cutrell, R. Jeffries, \& G. Olson (Eds.), proceedings of the SIGCHI conference on Human Factors in computing systems (CHI '06), New York, NY, USA: ACM, 2006, pp. 571-580.

[9] A., Kansal, M., Goraczko and F., Zhao, "Building a sensor network of mobile phones," in proceedings of the 6th international conference on Information processing in sensor networks (IPSN '07), New York, NY, USA: ACM, 2007, pp. 547-548.

[10] R., Bose, "Sensor networks motes, smart spaces, and beyond, pervasive computing,” IEEE 8(3), 2009, pp. 84 - 90.

[11] M., Sharples, Foreword, "Education in the wild: contextual and location-based mobile learning in action,”, in E. Brown (Ed.) Nottingham: Learning Sciences Research Institute, University of Nottingham, 2010, pp. 4-6.

[12] J., Voogt and N. J., Roblin, “21st century skills,” discussion paper, Enschede: University of Twente, 2010.

[13] M., Bistrup, M., Haines, S., Hygge, D., MacKenzie, S., Neyen and C., Petersen, C., "Children and noise - prevention of adverse effects,” National Institute of Public Health, Denmark, ISBN: 877899-056-4, 2002.

[14] P., Lonsdale, C., Baber, M., Sharples and T. N., Arvantis, “A context-awareness architecture for facilitating mobile learning," in J. Attewell \& C. Savill-Smith (Eds.), Learning with mobile devices, Research and development, London: Learning and Skills Development Agency, 2004, pp. 79-86.

[15] A., Syvanen, R., Beale, M., Sharples, M., Ahonen and P., Lonsdale, "Supporting pervasive learning environments: adaptability and context awareness in mobile learning,” IEEE International Workshop on Wireless and Mobile Technologies in Education, WMTE 2005, 2005.

[16] H-C., Chu, G-J., Hwang, Y-R., Shi, C-I., Lee and W-W., Chien, "A conceptual map-oriented mindtool for conducting collaborative ubiquitous learning activities,” in S. C., Kong et al. (Eds.), proceedings of the 17th International Conference on Computers in Education, Hong Kong: Asia-Pacific Society for Computers in Education, 2009, pp. 559-563. 
[17] J., Yau and M., Joy, M., “A mobile and context-aware adaptive learning schedule framework from a usability perspective - a 'diary: diary-questionnaire’ study,” in S. C., Kong et al., (Eds.), proceedings of the 17th International Conference on Computers in Education, Hong Kong: Asia-Pacific Society for Computers in Education, 2009, pp. 512-519.

[18] B. J., Fogg, “Increasing persuasion through mobility," in Mobile Persuasion - 20 Perspectives on the Future of Behavior Change (Eds. B. J., Fogg and D., Eckles), Persuasive Technology Lab., Stanford University, 2007.

[19] T., Malone and M., Lepper, "Making learning fun: a taxonomy of intrinsic motivation for learning," in Aptitude, Learning, and Instruction (Eds. R. E., Snow and M. J., Farr), Hillsdale, N. J., Lawrence Earlbaum, 1987.

[20] S., Santini et al., "First experiences using wireless sensor networks for noise pollution monitoring," European Conference on Computer Systems: proceedings of the workshop on Real-world wireless sensor networks (REALWSN'08), ACM, 2008, pp. 61-65.

[21] N., Maisonneuve, M., Stevens, M., Niessen and L., Steels, "NoiseTube: Measuring and mapping noise pollution with mobile phones," in Information Technologies in Environmental Engineering, Environmental Science and Engineering, DOI 10.1007/978-3540-88351-7_16, Springer-Verlag, Berlin, Heidelberg, 2009. http://dx.doi.org/10.1007/978-3-540-88351-7_16

[22] E., Kanjo et al., "MobGeoSen: Facilitating personal GeoSensor data collection and visualization using mobile phones," in Personal Ubiquitous Computing Journal, vol. 12, no. 8, November 2008, published online: August 2007, pp. 599-607.

[23] P., Mohan, V., Padmanabhan and R., Ramjee, "Nericell: rich monitoring of road and traffic conditions using mobile smartphones," in Proceedings of the 6th ACM Conference on Embedded Networked Sensor Systems (SenSys 2008), ACM, 2008, pp. 323336.

[24] E., Miluzzo et al., "Sensing meets mobile social networks: the design, implementation and evaluation of the CenceMe application," in proceedings of the 6th ACM Conference on Embedded Networked Sensor Systems (SenSys 2008), New York, NY, USA: ACM, 2008, pp. 337-350.

[25] A., Misra, G., Essl and M., Rohs, "Microphone as sensor in mobile phone performance," in proceedings of the 8th International Conference on New Interfaces for Musical Expression (NIME 2008), Genoa, Italy, June 5-7, 2008.

[26] S., Eisenman, E., Miluzzo, N., Lane, R., Peterson, G., Ahn and A., Campbell, "The BikeNet mobile sensing system for cyclist experience mapping," in proceedings of the 5th International Conference on Embedded Networked Sensor Systems, Sydney, Australia, 2007, pp. $87-101$.

[27] M., Klatte, J., Hellbrück, J., Seidel and P., Leistner, "Effects of classroom acoustics on performance and well-being in elementary school children: a field study," in Environment and Behavior, September 2010, vol. 42, no. 5, pp. 659-692.

[28] IEEE Standard 100 Dictionary of IEEE Standards Terms, Seventh Edition, The Institute of Electrical and Electronics Engineering, New York, 2000, ISBN 0-7381-2601-2, page 288.

[29] S., Deterding, D., Dixon, R., Khaled and L., Nacke, "From game design elements to gamefulness: defining gamification," in proceedings of the 15th International Academic MindTrek Conference: Envisioning Future Media Environments, Tampere, Finland, 2011.

[30] J., Scheible and V., Tuulos, Mobile Python: Rapid prototyping of applications on the mobile platform, Wiley, ISBN: 978-0-47051505-1, 2007, 348 pp.

[31] N., Lane, E., Miluzzo, H., Lu, D., Peebles, T., Choudhury and A., Campbell, "A survey of mobile phone sensing," in IEEE Communications Magazine, September, 2010. pp. 140 - 150. http://dx.doi.org/10.1109/MCOM.2010.5560598

[32] N., Lazzaro, "Why we play games: 4 keys to more emotion," in Game Developer's Conference, San Jose, CA, 2004.

[33] A., L'Espérance, A., Boudreau, F., Gariépy and P., Bacon, "Noise reduction in day-care centres by reducing reverberation time: analyses and case studies (Réduction du bruit dans les CPE par la réduction du temps de réverbération : analyses et études de cas),” in Studies and Research Projects / Report R-463, Montréal, IRSST, Téléchargement gratuity, 2006, 69 pages.
[34] C., Truchon-Gagnon and R., Hétu, "Noise in day-care center for children,” in Noise Control Engineering Journal, 30, 1987, p. 5764. http://dx.doi.org/10.3397/1.2827703

[35] M., Picard and C., Boudreau, "Characteristics of noise found in day-care centers,” in J. Acous. Soc of Am., Abstract, 105(2), 1999, p.1127.

[36] M., Picard, "Revisiting speech interference in classrooms," in Audiology, 40, 2001, p. 221-244.

[37] A., Moodley, “Acoustic conditions in mainstream classrooms," in J. Br. Assoc. Teachers Deaf, 13, 1989, p. 48-54.

[38] E. Sala et al., "Vocal loading among day care center teachers," in Logoped Phoniatr Vocol, 27, 2002, pp. 21-28. http://dx.doi.org/10.1080/140154302760146943

[39] W. P., Schaufeli, M. P., Leiter, C., Maslach and S. E., Jackson, Maslach Burnout Inventory Manual, California: Consulting Psychologist Press, 1996.

[40] C. L., Cordes and T. W., Dougherty, "A review and an integration of research on job burnout," in The Academy of Management Review, 18(4), 1993, pp. 621-656.

[41] J., Blase, “A Sosial psychologian grounded theory of teachers stress and burnout," in Educational Administration quarterly, 18 (4), 1982, pp. 93-113. http://dx.doi.org/10.1177/0013161X820 $\underline{18004008}$

[42] C., Kyriacou, “Teacher stress: past and present," in J., Dunham and V., Varma (Eds.), Stress in Teachers, Past Present and Future, 1998.

[43] C., Kyriacou, “Teacher stress: directions for future research,” in Educational Review, 53, 2001, pp. 28- 35. http://dx.doi.org/ $\underline{10.1080 / 00131910120033628}$

[44] H., Ketamo and M., Suominen, "Learning-by-teaching in educational games,” in J., Luca and E., Weippl (Eds.), proceedings of World Conference on Educational Multimedia, Hypermedia and Telecommunications, Chesapeake, VA: AACE, 2008, pp. 29542969.

[45] A., Selin, J., Turunen and J., Tanttu, "Wavelets in recognition of bird sounds,” in EURASIP J. Appl. Signal Process, 1 (January), 2007, pp.141-141.

[46] M., Klatte, M., Wegner and J., Hellbrück, "Noise in the school environment and cognitive performance in elementary school children, part b - cognitive psychological studies," in Forum Acusticum, 2005, pp. 2071 - 2074.

[47] D., Shendell, C., Barnett and S., Boese, "Science-based recommendations to prevent or reduce potential exposure to biological, chemical, and physical agents in schools," in Journal of School Health, vol. 74, no. 10, 2004, pp. 390 - 396. http://dx.doi.org/10.1111/j.1746-1561.2004.tb06603.x

[48] P., Nelson, K., Kohnert and S., Sabur, "Classroom noise and children learning through a second language," in Language, Speech, and Hearing Service in Schools, vol. 36, July 2005, pp. 219 - 229. http://dx.doi.org/10.1044/0161-1461(2005/022)

[49] P., Miller and K., Shannon, "Young children's understanding of the effect of noise and interest level on learning," in Genetic Psychology Monographs, vol. 110(1), August 1984, pp. 71-90.

[50] M., Haines et al., "Qualitative responses of children to environmental noise," in Noise \& Health, A Bimonthly Interdiciplinary International Journal, vol. 5, issue 19, 2003, pp. 19 30.

[51] D., Lawrence, "Using music in the classroom," in Advanced Brain Technologies, 2001, pp. 9.

[52] A., Perttula, P., Tuomi, M., Suominen, A., Koivisto and J., Multisilta, "Users as sensors: creating shared experiences in cocreational spaces by collective heart rate," in proceedings of 14 th International Academic MindTrek Conference: Envisioning Future Media Environments, Tampere, Finland, October 6th- $8^{\text {th }}$, 2010.

\section{AUTHORS}

Arttu Perttula (arttu.perttula@tut.fi) is a researcher at the Tampere University of Technology in Pori, Finland (Tampere University of Technology, Pori Unit, P.O.Box 300, FI-28101 Pori, Finland). He got his Master of Science (M.Sc.) from the Tampere University of Technology 
PAPER

Persuasive Mobile Device Sound Sensing in a Classroom Setting

in 2007. His research is related to mobile human computer interaction. Perttula has been working in different research projects concentrating mainly on mobile social media, mobile learning and mobile games. In the year 2008, Perttula spent six months with Fuji Xerox Palo Alto Laboratory, Inc. as an intern. In the year 2010 Perttula was a visiting researcher at Stanford University, H-STAR Institute (three months).

Jari Multisilta (jari.multisilta@helsinki.fi) is the director of Cicero Learning Network in University of Helsinki (University of Helsinki, P.O. Box 9, FI-00014, Helsinki, Finland), Finland, professor of multimedia in Tampere University of Technology, Information Technology at Pori, Finland, Nokia Visiting Professor and Visiting Scholar at Stanford University. He got his M.Sc. from the University of Tampere in 1992 in Mathematics and his Dr. Tech. at Tampere University of Technology in 1996. The title of his doctoral thesis was "Hypermedia Learning Environment for Mathematics". Prof. Multisilta has studied learning and modern communication and information technologies and has taken part in several research projects on this area. Currently, his research interests include networked and mobile learning, mobile social media, mobile storytelling, and mobile social video applications, especially panoramic video. Professor Multisilta has published over 100 international conference papers and journal articles on his research area. He was a Visiting Fellow at Nokia Research Center on 2008-2009. Multisilta has also been Visiting Scholar at Stanford University, H-STAR Institute for 2007 (2 months), 2008 (1 month), 2010 \& 6 months) and 2012 (2 months).

Pauliina Tuomi (pauliina.tuomi@tut.fi), Master of Arts, is a PhD student in Digital Culture at the University of Turku and works as a researcher at the Tampere University of Technology (Tampere University of Technology, Pori Unit, P.O.Box 300, FI-28101 Pori, Finland). Tuomi has been working in different research projects concentrating mainly on mobile learning and game-based learning innovations. Her doctoral thesis concentrates on interactive TV and it is set to define the different characteristic elements of participatory and intermedial TV culture in the 21st century. Her research interests include iTV-entertainment, participatory media culture and mediated communication.

This work was supported in part by the Nokia Foundation. Received 11 September 2012. Published as resubmitted by the authors 20 December 2012 